\title{
Digital Competences and Skills in the Frame of Education and Training
}

\author{
Valentina Milenkova ${ }^{1, *}$, Boris Manov ${ }^{1}$ \\ ${ }^{1}$ South-West University, Blagoevgrad, Bulgaria \\ *Corresponding author
}

\begin{abstract}
Keywords: Digital Literacy, Digital Competence and Skills, Digitization, Education
\end{abstract} Methods.

\begin{abstract}
Digital competence is increasingly a significant foundation for a modern knowledge society that operates in compressed space and time, in conditions of high mobility, interchangeability of many tools and resources, and in the saturation of information sources. The Empirical data are obtained by qualitative methods: 30 in-depth interviews carried out with members of different social groups. The paper argues that digital literacy includes the ability to search, select and process information in computer and network sources, content creation, and Internet safety skills. The main conclusions are that more efforts needed to improve the educational methods to create digital competences of learners.
\end{abstract}

\section{Introduction}

Developing competencies is largely related to improving young people's skills. They become the focus of national and European policies aimed at social prosperity and the well-being of citizens, as well as economic competitiveness. A number of phenomena have occurred in recent years, which have changed the attitudes towards skills. They related to the accelerated technological development, the prolonged period of active life, and the dynamic of social events. All this requires people to change their expectations, adapt their skills, and follow the challenges of different transitions.

Competences defined as a combination of knowledge, skills and attitudes applied appropriately to a context in order to achieve a desired outcome [1]. Key competences are those, which all individuals need for personal fulfilment, active citizenship, social cohesion and employability through lifelong learning in a knowledge society. The European Reference Framework [2] sets out eight key competences: Communication in the mother tongue; Communication in foreign languages; Mathematical competence and basic competences in science and technology; Digital competence; Learning to learn; Social and civic competences; Sense of initiative and entrepreneurship; Cultural awareness and expression.

The key competences all considered equally important, because each of them can contribute to a successful life in a knowledge society. Many of the competences overlap and interlock: aspects essential to one domain will support competence in another. Key competences show the impact of 
both national and regional policies as well as the efficiency of the educational institutions through which they are acquired. Key competences are important for the realization of both the individual and the community; they are a prerequisite for the development of national economies and knowledge societies in global perspective. Formation of creativity is related to the study contents that are taught in education institutions, to the specific rules and values in organizational aspect, to the contacts and sub-cultures, which training develops and draws individuals into different relations. All those components accumulate definite experience in themselves and they become bearers of a particular purpose and engagement devoted to shape in accordance to social pattern, which determines them.

This article analyzes the importance of digital competence, which is key in today's global society. It is clear that many of the traditional forms of learning, careers and daily life of people change under the conditions of digitization. Therefore, digital literacy and skills are fundamental to individuals, communities and institutions. The analysis reveals the essence of digital competence and skills as well as the responsibility of contemporary education for their formation in young people. Digital competence and its significance are examined in Bulgarian context, based on the results of a conducted sociological survey in 2019.

\section{Digital Competence}

The digital competence is the essential part of key competencies in the current framework. There is a minimum of digital skills, which everyone should possess in order to be able to participate fully in society as well as in the labor market. As the digital technology is a part of our daily life, most people have access to the internet to take advantage of on-line services, training, networking, and information opportunities. The widespread use of digital devices provides people with access to a large amount of information, which creates a need for a set of management, integration and evaluation skills. In recent years, digital competence and skills have been of great interest in discussing what skills people need to have in the knowledge society [3]. The discussion on digital skills is in a lesser or greater degree related to the policies at global and national level. It is connected to the expectations towards qualifications in the labor market and has its roots in economic competition in which new technology is viewed as an opportunity and approach for solution.

Digital competence is a concept describing the skills associated with knowledge and mastery of technology, and application of these skills into professional and social life. In recent years, different terms have been used that have a similar meaning, with some particular emphasis being placed; such as "computer skills", "information and technological skills", "media and information competence" [4]. In some cases, terms are narrower, e.g. "Internet Skills" or "Computer Skills" [5]; in other cases, the terms are more general, for example "21st Century literacy", where emphasis is placed on the social skills that develop through the knowledge of digital technologies [6].

The wide variety of concepts reflects the rapid development of technology as well as the various fields of interest related to their deployment in all areas of professional, economic and cultural life. Digital tools also provide impetus for the development of teaching and library research. Approaches to digital skills and competences are dynamic due to emerging new technologies and their use in society. "A competency is more than just knowledge and skills. It involves the ability to meet complex demands, by drawing on and mobilizing psycho-social resources (including skills and attitudes) in a particular context" [7]. In addition, digital competence involves not only digital skills, but also social and emotional skills related to the use and understanding of digital devices. In this context, the digital competence concentrates the confident and critical use of information society technologies for work, leisure and communication. It is based on the core ICT skills, that is, the use of computers for the extraction, evaluation, storage, production, presentation and exchange of information, as well as communication and participation in Internet collaboration networks [8]. 
Digital competence is the attitude to be in line with rapid ICT changes. Digital skills are an indicator of the development of society, the level of competence of the population, the readiness to accept new challenges in the context of social transformations.

In summary, the concept of digital competence is an emerging and reinforcing concept related to technology development as well as to the political goals and expectations of citizenship in the knowledge society. It includes a variety of skills in several areas: education, media and communications, technology and computing, literacy and information science. Digital competence consists of: 1) technical skills for using digital technologies; 2) the ability to use new technologies in a targeted way for work, learning, and for everyday life as a whole in different directions; 3) ability to critically evaluate digital technologies and contents; 4) motivation to participate in digital culture [9].

\section{Acquiring the Digital Competences and Skills}

Education has a crucial role in the formation of competences and skills, as the process of acquiring abilities and skills for a specific professional, social and personal sphere, which takes place both in and out of education institutions. According to a survey of the National Statistical Institute [10] conducted at the end of $2017-67.3 \%$ of households in Bulgaria have access to the Internet and $63 \%$ have a desktop computer, laptop or tablet. The most active Internet users are young people aged 16-24, with $88.1 \%$ using computers or the internet every day. $90 \%$ of university graduates surf regularly on global networks. Most often students use computers (95.6\%) and 97.8\% regularly surf. These results have directed us to educational institutions, approaches, teaching and learning methods which are a part of mobile learning and are geared towards shaping digital skills so important in the modern world.

The digitization of educational processes refers to any form of learning and teaching that is based on some kind of technology. The inclusion of digital technologies in education takes place in several directions: the purchase of digital equipment; creating computer programs for learning purposes; inclusion in the training of information technology classes; conducting projects and forums on the issues on digitization of training.

In the foundation of modern educational approaches is laid the integration of information and communication tools and achievements. What integrates digital technologies is enhanced interactivity, based on the concepts of cooperative learning, collaborative learning, e-learning, for the achievement of digital literacy. A basic feature of these processes is the desire to achieve a kind of an autonomy of the individual student / pupil. That is why the attention of specialists focuses on the theories of learning and their application in the teaching of various subjects.

The following approaches and methods are implemented in education:

- Learning in experience and through experience. What characterizes the educational methods in the foundation of which underlies learning through experience and in experience is the creation of life-related situations. In this type of learning the problems which are close to the real life have an important place. Professionals talk about so-called authentic problems. Their solution allows them to create an educational environment in which the traditional roles of the teacher and the pupils change. Pupils master the material as role-playing activities, where they improve their socio-cultural competencies (to fulfil certain social roles in a particular socio-cultural context). This type of learning offers opportunities to use preliminary knowledge.

- Problem-based learning is related to solving cognitive problems. In organizing it, the model of scientific knowledge follows, it is realized through the following stages:

a. Identifying the general subject by the teacher, but it can also be formulated by the pupils. Its importance and relevance is important for the pupils involved in the research. 
b. Decomposing the general topic of micro-topics and each group chooses their micro topic to work. This can be done through brainstorming and a through a conceptual network (the key words and logical links between them).

c. Planning and implementing the research process.

d. Data collection and preparation of a report on the activity carried out.

e. Presentation of the development through a computer presentation.

f. Assessment of the presentation of each group of the other participants. Criteria are discussed in advance are used, and they are accepted by all participants.

- Global-oriented learning is a conception based on inter-subject relations. The cross-border nature of cognitive activities carried out by students is a favorable prerequisite for improving their socio-cultural competences as well as the use of knowledge acquired on different subjects and aimed at achieving a higher level of education.

\subsection{Empirical Framework}

The project aimed at studying digital literacy was the national survey "Digital Media Literacy in the context of "Knowledge Society": state and challenges", funded by National Science Fund Bulgaria, with team leader V.Milenkova. The empirical data are obtained by $\mathbf{3 0}$ in-depth interviews carried out with members of different social groups: researchers, students, teachers, NGO and public agents. Topics discussed included: digitization and its features, digital competence, skills and literacy, the contribution of education to form digital literacy.

According to our respondents, digitization has actively penetrated people's lives, both in the personal and professional, and social spheres. It has become a very important part of the activities of institutions at different levels and in different fields. The data show that business, public and non-governmental sectors use systematically various digital assets and services in their activities. This means that digitization is ubiquitous and global, it changes generations and their thinking, attitudes and qualities; it affects and reformats social structures and relationships, imposing them on digital technology requirements. We present several views of respondents:

"Digitization and the use of new technologies are in all spheres of personal, social, political, cultural, academic, and other spheres of life. Digitization of society, however, is something more - in fact it expresses the degree of maturity, progressiveness and entrepreneurship of its individual members" (Female, 37, university lecturer).

Digitization of society is an indisputable fact and this is definitely a prerequisite for social development because it means providing new opportunities for the development of institutions as well as for forming new skills and qualities.

"Digitization is an inevitable and fundamental premise for the development of knowledge society, because it extends the possibilities of knowledge, i.e. the possibilities for its transfer, for its learning and its finding. In practice, it is not possible to achieve a knowledge society without the digitization of activities, and without the connectivity of entities and institutions which the digital environment permits through the social networks "(Female, 55, NGO).

The development of digital skills and literacy among young people depends to a large extent on the participation of education. Computer technologies are present in abundance at schools. Teachers assign homework that requires online research and online instruments, and they use software applications to manage these homework assignments. There are a number of examples in this direction which indicate that digital technologies are entering and changing the existing methods of training and teaching in educational institutions.

"I believe that digitization has entered education. Examples are computer literacy classes, digital "black" boards, and so on". (Male, 64, public organization). 
Education is also a conservative environment that affects not only the material conditions but also the teachers themselves and their methods; which means that sometimes there may be a lag in the teaching and learning methods used by teachers to incorporate innovative approaches that would negatively impact the acquisition of digital content and the formation of digital skills and literacy among students. Respondents share that the Bulgarian education is being digitized, but not always the digital devices which have been purchased are actively used and become the real basis for innovation in the educational process.

"According to me, the digitization of contemporary Bulgarian education is currently focused mainly on the physical acquisition of new technologies and, to a very small extent, in their functional use to acquire new digital competences, and not to learn and consolidate fundamental knowledge." (Female, 34, PR in a public organization).

More consistency, continuity and activity is needed for the real digitization of education and its grounding on successful practices and methods.

\section{Summary}

Digitization is valued as an important process that has actively penetrated society by changing all areas of political, professional, social life and personal relationships and activities of people.

Digitization is a part of education, but there is still a sporadic and not yet purposeful and organized nature. More systematic action is needed, longer-term vision, more focused strategies on how to develop digital skills and literacy of individuals. Bulgarian education is not always able to meet the new requirements and to take effective account of changes. Engaging young people in short-term or long-term courses could also contribute to their acquirement of important knowledge and qualities related to digital skills. One must not underestimate the conducting of seminars and lecture courses, the possibility of access to online tutorials, electronic textbooks and other means of enhancing digital competence; through these means, it is possible to develop extensive skills for seeking, identifying and critically assessing and using information, and for young people's more independent and creative behavior in a digital environment. For the formation of digital culture, it is of great importance to saturate the work environment with computers, and to include the Internet in the specific responsibilities of those performing different activities. The results showed that the family and education environment as well as teachers' attitudes are identified as factors of digital literacy of students. In this sense, complicating the responsibilities, the work and the nature of the educational involvements become prerequisites for the formation of digital literacy of the young people.

\section{Acknowledgement}

The article was developed under the project "Digital Media Literacy in the context of "Knowledge Society": state and challenges" № КП-06-H25/4, funded by National Science Fund - Bulgaria.

\section{References}

[1] D. Rychen, L. Salganik (Eds). Key competencies for a successfull life and a well-functioning society. Hogrefe Publishing, 2003.https://pubengine2.s3.eu-central- 1.amazonaws.com/preview/ 99.110005/ 9781616762728 preview.pdf

[2] The European Reference Framework

http://eur-lex.europa.eu/legal-content/EN/ALL/?uri=CELEX\%3A32006H0962. 
[3] J. Sefton-Green, H.Nixon \& O.Erstad, Reviewing approaches and perspectives on "Digital literacy“. Pedagogies, 2009, 4(2): 107-125

[4] E.Adeyemon, Integrating digital literacies into outreach services for underserved youth populations. Reference Librarian, 2009, 50(1): 85-98

[5] B. Jones-Kavalier, S.L. Flannigan, Connecting the digital dots: Literacy of the 21st century. Teacher Librarian, 2008, 35 (3): 13-16

[6] H. Jenkins, K.Clinton, P.Purushotma, A.J.Robinson \& M.Weigel, Confronting the Challenges of Participatory Culture: Media Education for the 21st Century, 2006. The J.D. \& C.T. MacArthur Foundation.http://www.digitallearning.macfound.org/atf/cf/\%7B7E45C7E0-A3E0-4B89-AC9C-E8 07E1B0AE4E\%7D/JENKINS WHITE PAPER.PDF

[7] The OECD Program Definition and Selection of Competencies. The definition and selection of key competencies. Executive summary. 2005, http: // www. oecd. org/ dataoecd/47/ 61/3507 0367.pdf.

[8] Y. Punie, M. Cabrera (Eds.) The Future of ICT and Learning in the Knowledge Society. Luxembourg: European Commission, 2006

[9] A. M. R. Correia, J. C. Teixeira, Information literacy: an integrated concept for a safer internet, Online Information Review, 2003, 27 (5): 311-20.

[10] National Statistical Institute data from 2017

https://www.mediapool.bg/32-ot-domakinstvata-u-nas-nyamat-dostap-do-internet-news272863.html 